OPEN ACCESS

Edited by:

Fuat BalCl,

Koç University, Turkey

Reviewed by:

Deana Davalos,

Colorado State University,

United States

Klaus Mathiak,

RWTH Aachen University, Germany

*Correspondence:

Chuan-Yue Wang

wang.cy@163.net

Received: 13 August 2018 Accepted: 13 February 2019

Published: 06 March 2019

Citation:

Xiong $Y$-B, Bo Q-J, Wang $C-M$,

Tian Q, Liu Y and Wang C-Y (2019) Differential of Frequency and Duration Mismatch Negativity and Theta Power Deficits in First-Episode and Chronic

Schizophrenia.

Front. Behav. Neurosci. 13:37. doi: 10.3389/fnbeh.2019.00037

\section{Differential of Frequency and Duration Mismatch Negativity and Theta Power Deficits in First-Episode and Chronic Schizophrenia}

\author{
Yan-Bing Xiong1,2,3,4, Qi-Jing Bo 1,2,3,4, Chang-Ming Wang 1,2,3,4, Qing Tian',2,3,4, Yi Liu11,2,3,4 \\ and Chuan-Yue Wang ${ }^{1,2,3,4 *}$

\begin{abstract}
'Department of Psychiatry, Beijing Anding Hospital, Capital Medical University, Beijing, China, ${ }^{2}$ Beijing Key Laboratory of Mental Disorders, Beijing, China, ${ }^{3}$ Beijing Institute for Brain Disorders Center of Schizophrenia, Beijing, China, ${ }^{4}$ The National Clinical Research Center for Mental Disorders, Beijing, China
\end{abstract}

Background: Due to its impairment in patients with schizophrenia, mismatch negativity (MMN) generation has been identified as a potential biomarker for identifying primary impairments in auditory sensory processing. This study aimed to investigate the dysfunctional differences in different MMN deviants and evoked theta power in patients with first-episode schizophrenia (FES) and chronic schizophrenia (CS).

Methods: We measured frequency and duration MMN from 40 FES, 40 CS, and 40 healthy controls $(\mathrm{HC})$. Evoked theta power was analyzed by event-related spectral perturbation (ERSP) approaches.

Results: Deficits in duration MMN were observed in both FES ( $p=0.048$, Bonferroniadjusted) and CS ( $p<0.001$, Bonferroni-adjusted). However, deficits in frequency MMN were restricted to the CS ( $p<0.001$, Bonferroni-adjusted). Evoked theta power deficits were observed in both patient groups when compared with the HC $(p$ FES $=0.001$, $p$ cs $<0.001$, Bonferroni-adjusted), yet no significant differences were found between FES and CS. Frequency MMN was correlated with the MATRICS consensus cognitive battery (MCCB) combined score $(r=-0.327, p<0.05)$ and MCCB verbal learning $(r=-0.328, p<0.05)$ in FES. Evoked theta power was correlated with MCCB working memory in both FES $(r=0.347, p<0.05)$ and CS $(r=0.408, p<0.01)$.

Conclusion: These findings suggest that duration $\mathrm{MMN}$ and evoked theta power deficits may be more sensitive for detection of schizophrenia during its early stages. Moreover, frequency MMN and theta power could potentially linked to poor cognitive functioning in schizophrenic patients. The findings mentioned above indicated that the neural mechanisms of the three indexes may vary between people.

Keywords: schizophrenia, mismatch negativity, first-episode schizophrenia, chronic schizophrenia, time-frequency analysis 


\section{INTRODUCTION}

One of the central features of schizophrenia is cognitive impairment (Elvevåg and Goldberg, 2000; Weickert et al., 2000), which may include both higher-order functions, such as working memory, and essential sensory functions like auditory function (Javitt and Freedman, 2015; Javitt and Sweet, 2015). Mismatch negativity (MMN) is a negative component of the auditory eventrelated potential (ERP), which may be indicative of the neural mechanisms of cognitive dysfunction that occur in patients with schizophrenia (Näätänen et al., 2014; Hay et al., 2015, Javitt and Sweet, 2015). In addition, MMN is a key component of auditory and visual change detection in the environment (Randeniya et al., 2018). MMN deficits have been identified in patients with firstepisode schizophrenia (FES; Hermens et al., 2010; MondragónMaya et al., 2013), patients with chronic schizophrenia (CS; Salisbury et al., 2002; Magno et al., 2008), and ultra-high risk individuals (UHR; Higuchi et al., 2014; Perez et al., 2014). In return, MMN has been proposed as a biomarker for the early detection of patients with schizophrenia.

Auditory MMN is typically induced by a response to the auditory oddball paradigm in which repeating standards are interrupted by rare deviant stimuli, which could differ from the standards for multiple characteristics (Näätänen et al., 2001). MMN deficits have been widely investigated in relation to frequency and duration MMN deviants in patients with schizophrenia. However, the relative degree of these deficits remains to be elucidated (Avissar et al., 2017). Previous studies (Salisbury et al., 2002; Magno et al., 2008) found that frequency MMN deficits were common in CS, yet these deficits were not detected in FES. However, duration MMN deficits have been detected in both FES and CS. For this reason, frequency MMN may be an unreliable biomarker for diagnosing patients with schizophrenia during the early stages of this disease, especially when compared with duration MMN (Haigh et al., 2017).

Despite providing comprehensive information at a physiological level, ERP analyses of MMN offer limited regional details. In contrast to ERP analysis, neuro-oscillatory (eventrelated spectral perturbation, ERSP) approaches can provide information about underlying ERP disturbances at the circuit and molecular levels simultaneously (Javitt and Sweet, 2015). Previously, auditory MMN was shown to have primary evoked power within the theta frequency band (4-7 Hz) (Fuentemilla et al., 2008; Hsiao et al., 2009, Javitt, 2015), which is the band closely tied to the function of somatostatin (SST)-expressing (Womelsdorf et al., 2014) and multipolar bursting-type (Blatow et al., 2003) GABA interneurons. Some studies have already found that MMN-evoked theta power was impaired in patients with schizophrenia (Javitt et al., 2017). However, no studies have reported whether there is a difference in evoked theta power deficits between FES and CS.

In order to study the mechanism of MMN impairment in patients with schizophrenia, researchers associate it with clinical symptoms and cognition. When pertaining to the symptom domains in schizophrenia, relations to MMN amplitude deficits have not been detected at this time. Some reports have shown that negative symptoms may be associated with MMN deficits
(Grzella et al., 2001; Salisbury et al., 2002), while other studies have found an association with positive symptoms (Thönnessen et al., 2008; Fisher et al., 2011). However, one meta-analysis failed to detect a relationship between MMN amplitude deficits and symptom domains (Umbricht and Krljes, 2005). Interestingly, antipsychotic drugs do not improve MMN amplitude (Umbricht et al., 1999; Oranje et al., 2017). D-serine, which functions as an endogenous ligand for the glycine modulatory site of the N-methyl-d-aspartate-type (NMDAR), was previously found to improve MMN amplitude in patients with schizophrenia (Kantrowitz et al., 2017). More importantly, many studies have also repeatedly demonstrated that NMDAR antagonists (ketamine or MK-801) can reduce MMN (Catts et al., 2016), suggesting that MMN generation is associated with NMDAR, but not dopamine receptors.

Recently, researchers have shifted their focus to the correlation between MMN measures and cognition impairment. Some studies reported significant correlations between duration MMN amplitude and cognitive functioning in the domains of verbal fluency (Higuchi et al., 2013), social cognition (Wynn et al., 2010), and executive functioning (Toyomaki et al., 2008). However, a recent study reported significant relationships between MMN amplitude with frequency deviants and cognitive function in the verbal learning domain, but there were no significant relationships with duration deviants (Lee et al., 2017b). Regarding MMN-evoked theta power, D-serine treatment can also significantly improve theta response (Kantrowitz et al., 2016). More specifically, the improvement in theta occurs during the preparation interval, which correlates explicitly with an increase in auditory cognitive abilities (Kantrowitz et al., 2017).

In general, MMN amplitude deficits have been observed in patients with schizophrenia. However, the basis for the difference between frequency and duration MMN deficits in patients with schizophrenia remains to be elucidated. In this study, we hypothesized that the neural mechanisms of duration and frequency MMN deficits are different and deficits occur during various stages of schizophrenia. Therefore, we collected frequency and duration MMN amplitude data from FES and CS to verify our hypothesis. Meanwhile, we used ERSP approaches to acquire the evoked power to the MMN standard stimulus. To the best of our knowledge, this is the first study to concurrently assess the electrophysiological indices of evoked power in both FES and CS. We hypothesized that the evoked power deficits in CS are worse than the FES, similar to the MMN amplitude. Lastly, we analyzed the relationship between MMN measures (amplitude and evoked theta power) and clinical symptoms, sociodemographic measures and cognition impairments to further explore the neural mechanism.

\section{MATERIALS AND METHODS}

\section{Participants}

Eighty-five patients with schizophrenia were recruited from Beijing Anding Hospital, Capital Medical University. For inclusion in this study, the diagnoses were validated with the Structured Clinical Interview for DSM-IV (SCID). FES was 
classified as appearing within three years of entry into this study, while CS appeared more than five years before entry into this study. HC were recruited by advertisement and had no DSM-IV axis I disorders.

The age range was $18-45$ years old, and all participants had IQs $\geq 70$. The exclusion criteria for this study included hearing disorders, learning disabilities, neurological impairments, and histories of seizures, head injuries, electroconvulsive therapy, and drug abuse. The Ethics Committee of Beijing Anding Hospital reviewed and approved this study and all subjects provided informed consent prior to inclusion.

\section{Procedures}

The auditory stimuli consisted of a sequence of binaural tones (825 trials) that were presented in random order with a stimulus onset asynchrony of 500-550 ms. Standard tones (675 trials, 82\%) were $1000 \mathrm{~Hz}, 75 \mathrm{~dB}$, and $50 \mathrm{~ms}$ in duration. Deviant tones included frequency and duration deviants. Frequency deviants (75 trials, 9\%) were $1500 \mathrm{~Hz}, 75 \mathrm{~dB}$, and $50 \mathrm{~ms}$ in duration. Duration deviants (75 trials, 9\%) were $1000 \mathrm{~Hz}, 75 \mathrm{~dB}$, and $100 \mathrm{~ms}$ in duration. At the beginning of the paradigm, the first 15 stimuli were used as the standard.

\section{Electroencephalogram (EEG) Data Acquisition and Processing}

Electroencephalogram (EEG) data were collected from all of the subjects using the 128-channel electrode system (Electrical Geodesics, Inc., Eugene, OR, United States) with ground procedures and standard reference. The impedance of the signal was adjusted to $\geq 50 \mathrm{~K} \Omega$ with a sampling rate of $1000 \mathrm{~Hz}$. During the experiment, the subjects were seated comfortably in a light and sound-attenuated room to remove potentially interfering variables from the study. The test consisted of three sections with a $60 \mathrm{~s}$ break between each section.

For the ERP analyses, the EEG data were analyzed and processed using EEGLAB $14.1 .1 b^{1}$, which is a neural electrophysiological analysis tool based on MATLAB (MathWorks, Natick, MA, United States). The EEG data were processed using a $0.1-40 \mathrm{~Hz}$ bandpass filter (finite impulse response filter). The $50 \mathrm{~Hz}$ power frequency noise was subject to notch processing. The reference electrode was changed to a global brain average reference. Artifacts due to eye movement were excluded by independent component analysis (ICA; Makeig et al., 1997). The EEG was segmented from $100 \mathrm{~ms}$ prior to initiation to $500 \mathrm{~ms}$ after the stimulus onset. MMN waveforms were collected by subtracting the standard from the deviant stimulus at the frontal midline (Fz) electrode (Figures 1A,B).

For evoked (average) power analyses, ERP waves were transformed with the short-time Fourier transformation (STFT) method using MATLAB (MathWorks, Natick, MA, United States). Continuous wavelet transformation was carried out for the segmented EEG signal time. The EEG time range was from $100 \mathrm{~ms}$ before initiation to $500 \mathrm{~ms}$ after the stimulus onset, which was relative to the stimulus presentation time. The frequency range of the wavelet transformation was $1-20 \mathrm{~Hz}$. Additionally, the temporal values of power corresponding to each frequency point were averaged across the trials, and thus EEG power time-frequency distribution was attained channel by channel. We extracted the maximum power values between

${ }^{1}$ http://sccn.ucsd.edu/eeglab/
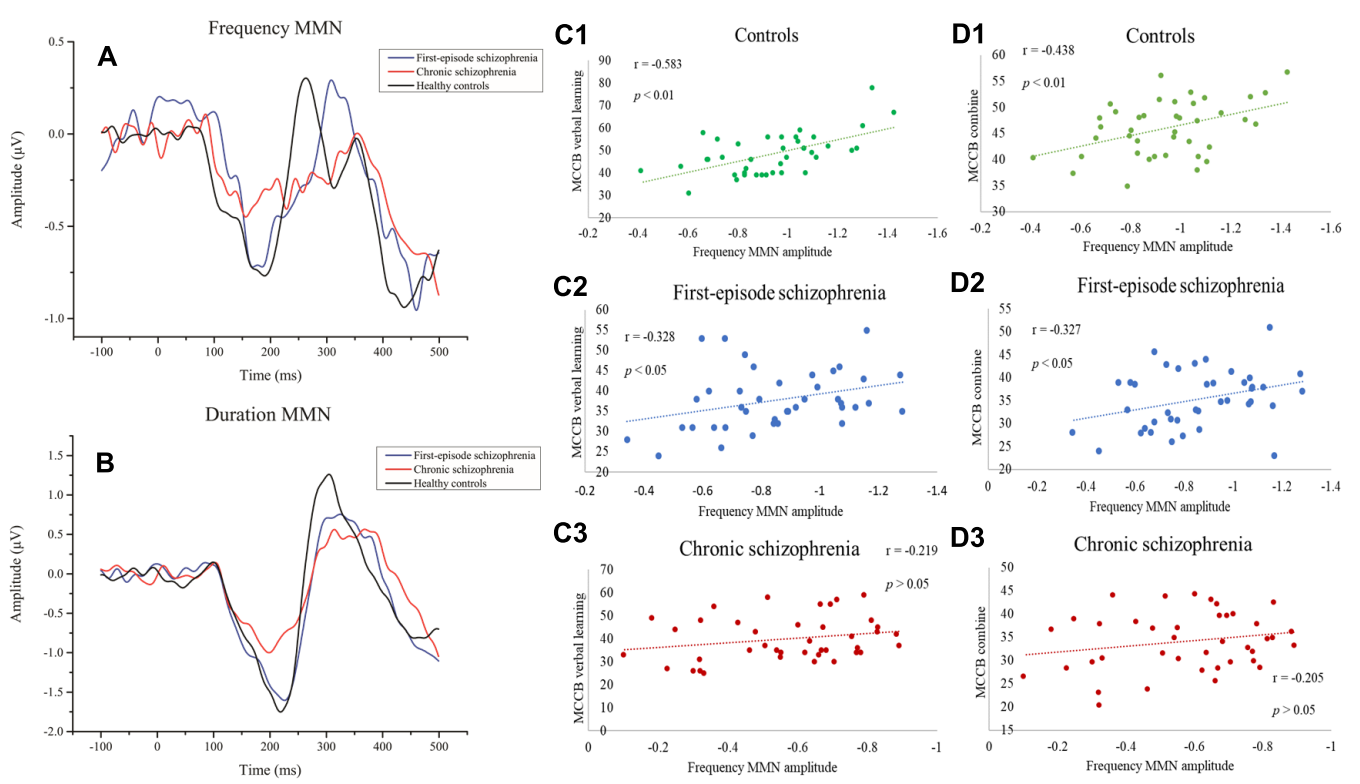

FIGURE 1 | (A) Event-related potential (ERP) waveforms to frequency deviant stimuli. (B) ERP waveforms to duration deviant stimuli. (C1-C3) Correlations between frequency MMN and MCCB verbal learning showing a significant relationship with the healthy control group and first-episode schizophrenia group. (D1-D3) Correlations between frequency MMN and the mean MCCB combined score showing a significant association between the healthy control group and the first-episode schizophrenia group. 
1-20 Hz and 100-250 ms of each subject for statistical analysis, and the range of the maximum value is within the theta frequency band of 4-7 Hz. We considered the theta frequency band to be the primary active frequency band of the nerve oscillation to the standard stimulus (Figures 2A1-A3).

\section{Clinical, Intelligence Quotient and Neuropsychological Assessment}

The clinical symptoms of each patient were evaluated with the Positive and Negative Symptom Scale (PANSS, Chinese version), which was described previously ( $\mathrm{He}$ and Zhang, 1997). The Chinese intelligence quotient (IQ) test tool is a revised short form of the Wechsler adult intelligence scale-revised, and the four included subsets for this evaluation were information, similarities, picture completion, and block design (Pang et al., 2011). The MATRICS consensus cognitive battery (MCCB, Chinese version) was used to evaluated cognitive deficits in patients with schizophrenia and healthy controls (Shi et al., 2015).

\section{Statistical Analysis}

Data analyses were performed using SPSS 20.0 (IBM, Chicago, IL, United States). Continuous variables were checked using one-way analysis of variance (ANOVA) and classified variables using the Chi-square test. Analysis of covariance was used to adjust for confounding effects of cognition among groups. A twofactorial mixed ANOVA with deviant type as within-subject factor and the between-subject factor groups was carried out. Associations between MMN values and the scores from the MCCB tasks or the PANSS scale were analyzed using Pearson's correlation analysis. The statistical test used a significance level of $p<0.05$. $P$-values were corrected using Bonferroni adjustment (B-adjusted). Cohen's effect size was used to analyze the differences between the means of each group. Measurement of the effect size was based on the Cohen coefficient (Cohen, 1988) with $d<0.2$ as a negligible effect size, $0.2-0.5$ as a small effect size, $0.5-0.8$ as a medium effect size, and $d>0.8$ as a large effect size.

\section{RESULTS}

\section{Demographics and Clinical Characteristics of Patients}

Three FES and two CS were excluded from this study due to lowquality EEG data. In total, $40 \mathrm{FES}, 40 \mathrm{CS}$, and $40 \mathrm{HC}$ were enrolled in the study. The demographic characteristics and clinical data for the remaining participants are summarized in Table 1. There were no significant differences in age $(d f=2,117, F=2.742$, $p=0.069)$, gender $\left(\chi^{2}=1.364, p=0.506\right)$, or education $(d f=2$, $117, F=1.476, p=0.233)$ among the three groups.

As expected, the HC had a higher IQ $(d f=2,117, F=11.667$, $p<0.001)$ and better MCCB task performance than FES and CS. The MCCB domain scores and statistical analyses are shown in Table 2. In analyzing covariance for IQ, the differences among groups remained significant for all the MCCB domains $\left(d f=2,117, F_{\text {speed of processing }}=27.548, p<0.001\right.$; $F_{\text {attention } / \text { vigilance }}=37.489, p<0.001 ; F_{\text {working memory }}=13.318$, $p<0.001 ; F_{\text {verbal learning }}=7.53, p=0.001 ; F_{\text {visual learning }}=3.69$, $p=0.028 ; F_{\text {reasoning and problemsolving }}=11.035, p<0.001$, $F_{\text {social cognition }}=3.321, p=0.04 ; \quad F_{\text {MCCB combine }}=$ 31.889, $p<0.001)$.

\section{Mismatch Negativity to Different Deviants}

Results showing the differences in frequency MMN, duration MMN, and standard ERSP between the three groups are shown in Table 3. More specifically, these findings describe the relative magnitude of MMN deficits between the groups. As predicted, there was a significant difference among the three groups in both
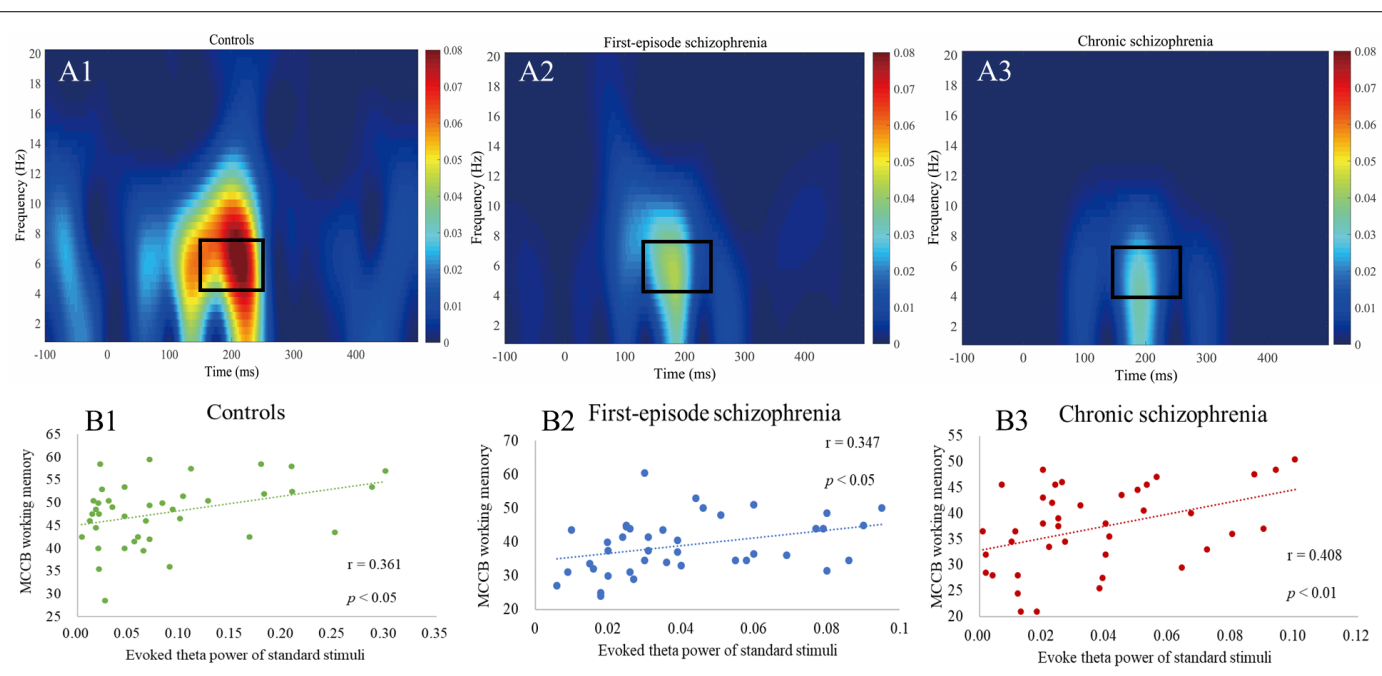

FIGURE 2 | (A1-A3) Evoked power plots for standard stimuli. Box indicates the integration window for the theta band response (4-7 Hz, 150-250 ms). (B1-B3) Correlations between evoked theta power and MCCB working memory showing a significant relationship between all three groups. 
TABLE 1 | Demographic and clinical characteristics of patients with first-episode schizophrenia, chronic schizophrenia, and healthy controls.

\begin{tabular}{|c|c|c|c|c|c|c|c|c|c|c|c|c|}
\hline \multirow[t]{3}{*}{ Variable } & \multicolumn{6}{|c|}{ Group } & \multicolumn{3}{|c|}{ Analysis } & \multicolumn{3}{|c|}{$\begin{array}{l}\text { post hoc Tests } p \text {, } \\
\text { Bonferroni-adjusted }\end{array}$} \\
\hline & \multicolumn{2}{|c|}{ FES $(N=40)$} & \multicolumn{2}{|c|}{$\operatorname{CS}(N=40)$} & \multicolumn{2}{|c|}{$\mathrm{HC}(N=40)$} & \multirow[t]{2}{*}{$d f$} & \multirow[t]{2}{*}{$\boldsymbol{F}$} & \multirow[t]{2}{*}{$p$} & \multirow[t]{2}{*}{ FES vs. CS } & \multirow[t]{2}{*}{ FES vs. HC } & \multirow[t]{2}{*}{ CS vs. HC } \\
\hline & Mean & $S D$ & Mean & $S D$ & Mean & $S D$ & & & & & & \\
\hline Age (years) & 25.63 & 6.21 & 28.50 & 5.34 & 26.33 & 5.60 & 2,117 & 2.742 & 0.069 & 0.08 & 1.000 & 0.276 \\
\hline Education (years) & 13.40 & 2.87 & 13.88 & 2.62 & 14.48 & 2.91 & 2,117 & 1.476 & 0.233 & 1.000 & 0.267 & 1.000 \\
\hline $\mathrm{IQ}$ & 101.48 & 12.403 & 105.58 & 9.732 & 114.1 & 13.345 & 2,117 & 11.667 & $<0.001$ & 0.381 & $<0.001$ & 0.005 \\
\hline $\begin{array}{l}\text { Age at illness onset } \\
\text { (years) }\end{array}$ & 24.48 & 6.27 & 21.35 & 4.84 & - & - & 1,78 & 6.231 & 0.015 & - & - & - \\
\hline $\begin{array}{l}\text { Duration of illness } \\
\text { (months) }\end{array}$ & 14.15 & 9.24 & 90.03 & 37.71 & - & - & 1,78 & 152.8 & $<0.001$ & - & - & - \\
\hline \multicolumn{13}{|c|}{ Positive and Negative Syndrome Scale } \\
\hline Positive scale score & 20.98 & 5.55 & 21.60 & 3.95 & - & - & 1,78 & 0.337 & 0.563 & - & - & - \\
\hline $\begin{array}{l}\text { Negative scale } \\
\text { score }\end{array}$ & 20.35 & 5.90 & 19.65 & 4.80 & - & - & 1,78 & 0.339 & 0.562 & - & - & - \\
\hline $\begin{array}{l}\text { General } \\
\text { psychopathology } \\
\text { score }\end{array}$ & 40.1 & 6.11 & 42.18 & 5.57 & - & - & 1,78 & 2.524 & 0.116 & - & - & - \\
\hline \multirow[t]{2}{*}{ PANSS score } & 81.43 & 12.33 & 83.43 & 10.25 & - & - & 1,78 & 0.622 & 0.433 & - & - & - \\
\hline & $\mathrm{N}$ & $\%$ & $\mathrm{~N}$ & $\%$ & $\mathrm{~N}$ & $\%$ & df & $x^{2}$ & $p$ & FES vs. CS & FES vs. HC & CS vs. HC \\
\hline Sex (Male, \%) & 28 & 70 & 23 & 57.5 & 25 & 62.5 & 2 & 1.364 & 0.506 & 0.245 & 0.478 & 0.648 \\
\hline \multicolumn{13}{|c|}{ Antipsychotic treatment } \\
\hline None & 24 & 60 & 4 & 10 & - & - & - & - & - & - & - & - \\
\hline $\begin{array}{l}\text { First-generation } \\
\text { antipsychotic }\end{array}$ & 0 & 0 & 0 & 0 & - & - & - & - & - & - & - & - \\
\hline $\begin{array}{l}\text { Second-generation } \\
\text { antipsychotic }\end{array}$ & 16 & 40 & 36 & 90 & - & - & - & - & - & - & - & - \\
\hline
\end{tabular}

${ }^{*}$ FES = First-episode Schizophrenia; CS = Chronic Schizophrenia; HC = Healthy Controls; IQ = intelligence quotient; - = Not Available.

TABLE 2 | MATRICS consensus cognitive battery (MCCB) domain-scores for first-episode schizophrenia, chronic schizophrenia, and healthy control groups.

\begin{tabular}{|c|c|c|c|c|c|c|c|c|c|c|c|c|}
\hline \multirow[t]{3}{*}{ Variable } & \multicolumn{6}{|c|}{ Group } & \multicolumn{3}{|c|}{ Analysis } & \multicolumn{3}{|c|}{$\begin{array}{l}\text { post hoc Tests } p \text {, } \\
\text { Bonferroni-adjusted }\end{array}$} \\
\hline & \multicolumn{2}{|c|}{ FES $(N=40)$} & \multicolumn{2}{|c|}{$\operatorname{CS}(N=40)$} & \multicolumn{2}{|c|}{$\mathrm{HC}(N=40)$} & \multirow[t]{2}{*}{$d f$} & \multirow[t]{2}{*}{$\boldsymbol{F}$} & \multirow[t]{2}{*}{$p$} & \multirow[t]{2}{*}{ FES vs. CS } & \multirow[t]{2}{*}{ FES vs. HC } & \multirow[t]{2}{*}{ CS vs. HC } \\
\hline & Mean & $S D$ & Mean & $S D$ & Mean & $S D$ & & & & & & \\
\hline Speed of processing & 35.88 & 7.65 & 34.88 & 8.09 & 48.18 & 6.13 & 2,117 & 40.778 & $<0.001$ & 1.000 & $<0.001$ & $<0.001$ \\
\hline Attention/Vigilance & 29.58 & 10.64 & 24.7 & 12.23 & 46.4 & 7.44 & 2,117 & 48.907 & $<0.001$ & 0.109 & $<0.001$ & $<0.001$ \\
\hline Working memory & 39.25 & 8.23 & 37.45 & 7.96 & 48.1 & 6.95 & 2,117 & 21.736 & $<0.001$ & 0.900 & $<0.001$ & $<0.001$ \\
\hline Verbal learning & 37.78 & 7.28 & 39.93 & 9.49 & 48.4 & 9.17 & 2,117 & 16.67 & $<0.001$ & 0.814 & $<0.001$ & $<0.001$ \\
\hline Visual learning & 41.83 & 11.32 & 39.2 & 11.68 & 48.5 & 11.5 & 2,117 & 7.738 & 0.001 & 0.851 & 0.021 & 0.001 \\
\hline $\begin{array}{l}\text { Reasoning and problem } \\
\text { solving }\end{array}$ & 33.28 & 10.57 & 33.53 & 8.59 & 45.6 & 9.87 & 2,117 & 21.054 & $<0.001$ & 1.000 & $<0.001$ & $<0.001$ \\
\hline Social cognition & 29.95 & 9.81 & 29.8 & 11.31 & 37.45 & 9.57 & 2,117 & 7.223 & 0.001 & 1.000 & 0.004 & 0.004 \\
\hline MCCB combine & 35.6 & 6.41 & 34.4 & 6.53 & 46.1 & 5.29 & 2,117 & 44.524 & $<0.001$ & 1.000 & $<0.001$ & $<0.001$ \\
\hline
\end{tabular}

*FES = First-episode Schizophrenia; CS = Chronic Schizophrenia; HC = Healthy Controls.

frequency $\mathrm{MMN}(d f=2,117, F=30.968, p<0.001)$ and duration $\operatorname{MMN}(d f=2,117, F=23.962, p<0.001)$.

When compared to $\mathrm{HC}$, there was no significant difference with FES in terms of frequency MMN ( $p=0.269$, Bonferroniadjusted), and the Cohen's effect size was small $(d=0.37)$. However, the difference was significant ( $p<0.001$, Bonferroniadjusted) and the Cohen's effect size was large $(d=1.72)$ when comparing CS with HC. Meanwhile, in terms of duration MMN, both FES ( $p=0.048$, Bonferroni-adjusted) and CS ( $p<0.001$, Bonferroni-adjusted) showed significant differences when compared with HC. The Cohen's effect size for FES and CS were approximately medium $(d=0.48)$ and large $(d=2.15)$, respectively. When the two patient groups were compared, there was a significant main effect for both frequency 
TABLE 3 | Mismatch negativity amplitudes and event-related spectral perturbation indexes.

\begin{tabular}{|c|c|c|c|c|c|c|c|c|c|c|c|c|c|c|}
\hline \multirow[t]{3}{*}{ Variable } & \multicolumn{6}{|c|}{ Group } & \multicolumn{3}{|c|}{ Analysis } & \multicolumn{3}{|c|}{$\begin{array}{c}\text { post hoc Tests } p \text {, } \\
\text { Bonferroni-adjusted }\end{array}$} & \multicolumn{2}{|c|}{ Cohen's d } \\
\hline & \multicolumn{2}{|c|}{ FES $(N=40)$} & \multicolumn{2}{|c|}{$\operatorname{CS}(N=40)$} & \multicolumn{2}{|c|}{$\mathrm{HC}(N=40)$} & \multirow[t]{2}{*}{$d f$} & \multirow[t]{2}{*}{$F$} & \multirow[t]{2}{*}{$p$} & \multirow[t]{2}{*}{ FES vs. CS } & \multirow[t]{2}{*}{ FES vs. HC } & \multirow[t]{2}{*}{ CS vs. HC } & \multirow[t]{2}{*}{ FES vs. HC } & \multirow[t]{2}{*}{ CS vs. HC } \\
\hline & Mean & $S D$ & Mean & $S D$ & Mean & $S D$ & & & & & & & & \\
\hline $\begin{array}{l}\text { Frequency } \\
\text { MMN }(\mu \mathrm{V})\end{array}$ & -0.8557 & 0.2295 & -0.57 & 0.2102 & -0.94 & 0.221 & 2,117 & 30.968 & $<0.001$ & $<0.001$ & 0.269 & $<0.001$ & 0.37 & 1.72 \\
\hline $\begin{array}{l}\text { Duration } \\
\text { MMN }(\mu \mathrm{V})\end{array}$ & -1.6366 & 0.4801 & -0.9146 & 0.3035 & -1.8893 & 0.5654 & 2,117 & 47.802 & $<0.001$ & $<0.001$ & 0.048 & $<0.001$ & 0.48 & 2.15 \\
\hline $\begin{array}{l}\text { Standard } \\
\text { ERSP }\end{array}$ & 0.0411 & 0.0249 & 0.0366 & 0.0276 & 0.0846 & 0.0793 & 2,117 & 10.98 & $<0.001$ & 1.000 & 0.001 & $<0.001$ & 0.74 & 0.81 \\
\hline
\end{tabular}

*FES = First-episode Schizophrenia; CS = Chronic Schizophrenia; HC = Healthy Controls; MMN = Mismatch Negativity.

MMN ( $p_{\mathrm{F}}<0.001$, Bonferroni-adjusted) and duration $\mathrm{MMN}$ ( $p_{d}<0.001$, Bonferroni-adjusted).

The results of two-factorial mixed ANOVA with the deviant type (frequency and duration) as within-subject and betweensubject factor groups (FES and CS) showed that the effects within subjects were significant $(F=167.023, p<0.001)$, and the effects between subjects were also significant $(F=75.835, p<0.001)$. The interaction effects with MMN type (frequency vs. Duration) * Group were also significant $(F=25.112, p<0.001)$.

The relationship between $\mathrm{MMN}$ amplitude and several variables, including sociodemographic variables, MCCB tests, and PANSS scale scores, are described in Tables 4, 5. As we expected, no significant correlations were found between MMN amplitude and sociodemographic variables or MMN amplitude and PANSS scale scores. In terms of the MCCB tests, both FES ( $r=-0.327, p=0.039$, Figure 1D2) and HC frequency MMN ( $r=-0.438, p=0.005$, Figure 1D1) were strongly correlated with overall cognitive functioning, as assessed by the combined MCCB scores. However, CS frequency MMN was not associated with overall cognitive functioning. Of the three groups, only the duration MMN $(r=-0.341, p=0.032)$ of the healthy control group was found to correlate with overall cognitive function. Among the individual MCCB items, the correlation between frequency MMN and verbal learning was detected in FES $(r=-0.328, p=0.039$, Figure 1C2) and HC $(r=-0.583$, $p<0.001$, Figure 1C1), yet it was not observed in CS. In contrast, HC showed weak correlations between duration MMN and speed of processing $(r=-0.326, p=0.04)$, as well as duration MMN and social cognition $(r=-0.335, p=0.034)$. However, when using the Bonferroni correction, only the correlation between frequency MMN and MCCB verbal learning in HC was statistically significant, suggesting that the respective correlations are only significant on a descriptive level.

\section{Evoked Theta Power to the Standard Stimulus}

The differences in evoked theta power among the three groups may be found in Table 3. There was also a significant difference among the three groups $(d f=2,117, F=10.98, p<0.001)$. Both patient groups showed significant reductions in the evoked theta power when compared with the HC $\left(p_{F E S}=0.001, p_{C S}<0.001\right.$, Bonferroni-adjusted), yet there was no significant difference between the two patient groups ( $p=1.000$, Bonferroni-adjusted). The Cohen's effect size for FES was medium $(d=0.74)$, while the Cohen's effect size for CS was large $(d=0.81)$.

As shown in Table 5, in terms of MCCB domain correlations, all three groups measures were significantly correlated with working memory $\left(r_{\mathrm{HC}}=0.361, p_{\mathrm{HC}}=0.022\right.$, Figure 2B1; $r_{\mathrm{FES}}=0.347, p_{\mathrm{FES}}=0.028$, Figure $2 \mathrm{~B} 2 ; r_{\mathrm{CS}}=0.408, p_{\mathrm{CS}}=0.009$, Figure 2B3). However, there were no statistically significant findings on the correlation analysis using the Bonferroni

TABLE 4 | Correlation between mismatch negativity measures with age, age at illness onset, duration of illness, and PANSS scores.

\begin{tabular}{|c|c|c|c|c|c|c|}
\hline \multirow[t]{2}{*}{ Variable } & \multicolumn{3}{|c|}{ FES $(n=40)(r)$} & \multicolumn{3}{|c|}{$\operatorname{cs}(n=40)(r)$} \\
\hline & Frequency MMN & Duration MMN & Standard ERSP & Frequency MMN & Duration MMN & Standard ERSP \\
\hline Positive scale score & 0.026 & -0.036 & -0.176 & -0.149 & 0.051 & -0.142 \\
\hline Negative scale score & 0.167 & 0.140 & 0.002 & 0.198 & 0.179 & $-0.395^{*}$ \\
\hline General psychopathology score & -0.074 & -1.113 & 0.025 & 0.159 & 0.118 & -0.144 \\
\hline PANSS score & 0.055 & -0.005 & -0.053 & 0.122 & 0.168 & $-0.318^{*}$ \\
\hline Age (years) & 0.022 & -0.057 & 0.228 & 0.09 & -0.185 & 0.176 \\
\hline Age at illness onset (years) & -0.007 & -0.062 & 0.256 & 0.202 & -0.140 & 0.193 \\
\hline Duration of illness (months) & 0.215 & 0.095 & -0.236 & -0.13 & -0.138 & 0.002 \\
\hline
\end{tabular}

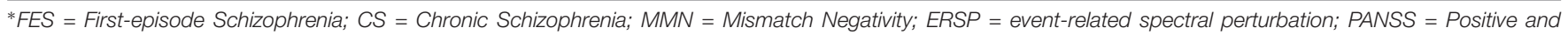
Negative Symptom Scale; * $p<0.05$. 
TABLE 5 | Correlation between mismatch negativity measures and the MATRICS consensus cognitive battery domain.

\begin{tabular}{|c|c|c|c|c|c|c|c|c|c|}
\hline \multirow[t]{2}{*}{ Variable } & \multicolumn{3}{|c|}{ FES $(n=40)(r)$} & \multicolumn{3}{|c|}{$\operatorname{cs}(n=40)(r)$} & \multicolumn{2}{|c|}{ HC $(n=40)(r)$} & \multirow[b]{2}{*}{$\begin{array}{c}\text { Standard } \\
\text { ERSP }\end{array}$} \\
\hline & $\begin{array}{c}\text { Frequency } \\
\text { MMN }\end{array}$ & $\begin{array}{l}\text { Duration } \\
\text { MMN }\end{array}$ & $\begin{array}{l}\text { Standard } \\
\text { ERSP }\end{array}$ & $\begin{array}{c}\text { Frequency } \\
\text { MMN }\end{array}$ & $\begin{array}{l}\text { Duration } \\
\text { MMN }\end{array}$ & $\begin{array}{l}\text { Standard } \\
\text { ERSP }\end{array}$ & $\begin{array}{c}\text { Frequency } \\
\text { MMN }\end{array}$ & $\begin{array}{l}\text { Duration } \\
\text { MMN }\end{array}$ & \\
\hline Speed of processing & -0.276 & -1.115 & 0.162 & -0.126 & -0.064 & 0.202 & -0.286 & $-0.326^{*}$ & 0.158 \\
\hline Attention/Vigilance & -0.301 & -0.066 & 0.191 & -0.179 & 0.072 & -0.257 & -0.136 & -0.036 & 0.091 \\
\hline Working memory & -0.146 & 0.01 & $0.347^{*}$ & -0.095 & -0.091 & $0.408^{* *}$ & -0.241 & -0.13 & $0.361^{*}$ \\
\hline Verbal learning & $-0.328^{*}$ & -0.008 & -0.193 & -0.219 & -0.084 & -0.052 & $-0.583^{* *}$ & -0.096 & 0.143 \\
\hline Visual learning & -0.192 & -0.105 & 0.084 & -0.292 & -0.156 & 0.16 & -0.059 & -0.218 & 0.2 \\
\hline $\begin{array}{l}\text { Reasoning and } \\
\text { problem solving }\end{array}$ & -0.227 & -0.04 & 0.16 & 0.087 & -0.216 & 0.309 & $-0.352^{*}$ & -0.285 & 0.139 \\
\hline Social cognition & -0.089 & -0.168 & 0.24 & -0.026 & 0.012 & 0.085 & -0.214 & $-0.335^{*}$ & 0.14 \\
\hline MCCB combine & $-0.327^{*}$ & -0.113 & 0.21 & -0.205 & -0.118 & 0.158 & $-0.438^{* *}$ & $-0.341^{*}$ & 0.271 \\
\hline
\end{tabular}

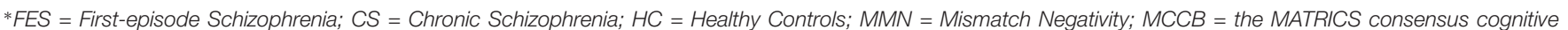
battery; ERSP = event-related spectral perturbation; * $p<0.05 ; * * p<0.01$.

correction, which indicated that the respective correlations were only significant on a descriptive level.

\section{DISCUSSION}

Mismatch negativity generation deficits have been recognized as one of the best potential biomarkers of cognitive impairment in patients with schizophrenia (Näätänen et al., 2016). While MMN deficits have been detected in several deviant types, the most extensively studied are those of duration and frequency, as both of these have been found to be significantly impaired in patients with schizophrenia (Friedman et al., 2012). Some researchers have found differential impairments in frequency and duration MMN and suggested that deficits in duration deviants may be more sensitive indices of $M M N$ reduction during the early stages of schizophrenia (Todd et al., 2008). In our study, compared to HC, frequency MMN was only impaired in CS, but duration MMN was impaired in both FES and CS. Therefore, our results confirmed this viewpoint. A recent meta-analysis (Haigh et al., 2017), which compared the results from several studies that measured MMN reduction in patients with first-episode schizophrenia-spectrum, showed a negligible effect size of 0.04 SD for MMN to frequency deviants and a small-to-medium effect size of $0.47 \mathrm{SD}$ for duration deviants. In the individuals at ultra-high risk (UHR; Koshiyama et al., 2017), duration MMN was significantly smaller when compared with the HC. However, frequency MMN did not differ between the UHR individuals and HC. These similar findings suggest that duration $\mathrm{MMN}$ is a better biomarker for the early identification of the patients with schizophrenia than frequency MMN.

Both frequency and duration MMN deficits in CS were more severe when compared with FES, and the within- and between-subject effects were also significant, suggesting that MMN amplitude deficits may correlate with the progression of the patients with schizophrenia. However, MMN deficits were not significantly associated with disease duration in either of the deviant types between the two patient groups, which is in agreement with a recent meta-analysis (Erickson et al., 2016).
One conceivable explanation is that MMN impairment worsens within the first 1 to 2 years after the diagnosis, but stabilizes after this critical period. Previously, Salisbury et al. (Salisbury et al., 2007) discovered a progressive course of MMN impairment during the initial 18 months of the disease. Nevertheless, our study did not find that MMN deficits in FES (mean duration of illness was 14.15 months) have any significant relationship with the length of illness. Another possible explanation to this controversy is that MMN deficits may be related to the age of the patients (Todd et al., 2008), yet several studies (Lee et al., 2017 b,c), including the current investigation, have shown no correlation between MMN and patient age. Additionally, we did not detect this association with age at illness onset.

While we showed that differential deficits in frequency and duration MMN between FES and CS remain controversial, the correlation study with MCCB showed that the neural processing mechanism of duration and frequency MMN might be different. The results of our study showed that frequency MMN deficits were related to MCCB verbal learning (T-score) in the $\mathrm{HC}$ and FES, yet duration MMN deficits were not significantly associated with any cognitive domains in MCCB from either group. This may suggest that frequency $\mathrm{MMN}$ is a potential marker that can be correlated with auditory functioning early on in patients with schizophrenia. Similarly, previous researchers found that frequency MMN is intact in FES (Haigh et al., 2017), especially in patients with high premorbid functioning (Salisbury et al., 2017). However, even in these patients, declines in frequency MMN occur over the first few years of the disease in parallel with structural changes in the auditory cortex (Javitt et al., 2000; Kasai et al., 2003). In summary, duration MMN may be related to premorbid aspects of patients with schizophrenia, while frequency $\mathrm{MMN}$ may be relevant to the decline in cognitive functioning that occurs during the early stages of patients with schizophrenia (Lee et al., 2017b).

Another important discovery of our study is that deficits in theta power response to standard stimuli were significantly impaired in both groups. Similarly, Lee et al. found that lower frequency oscillations were sparked, especially by the MMN, that may be mapped to the theta frequency range, and that 
these oscillations are impaired in patients with schizophrenia (Lee et al., 2017a, Lee et al., 2017c). However, their recent study (Lee et al., 2017b) also found that alpha power was significantly impaired in patients with schizophrenia. In return, low-range alpha and theta oscillatory frequencies may contribute to MMN, as they are all impaired in patients with schizophrenia. Our study also found that theta power responses to standard stimuli deficits could not distinguish between FES and CS. More interestingly, theta power response was significantly correlated with MCCB working memory in all three groups. A recent review proposed that theta frequency generation may be tied to the impaired interplay between the cortical pyramidal neurons and local circuit SST-type GABAergic interneurons (Javitt et al., 2017). In addition, another study suggested that working memory may be correlated with GABA levels in patients with schizophrenia (Chen et al., 2014), which may indicate that theta power response to standard stimuli is a marker of auditory working memory in patients with schizophrenia.

\section{CONCLUSION}

In conclusion, we show the differential MMN measures of deficits between FES and CS. Frequency MMN was not impaired in FES when compared with $\mathrm{HC}$, and it was correlated with MCCB verbal learning. Duration MMN and theta-evoked power were impaired in both patient groups. In addition, duration MMN deficits were not correlated with any MCCB domain, yet theta-evoked power deficits were correlated with MCCB working memory in all three groups. These results suggest that the mechanisms of frequency and duration mismatch negativity and theta power deficits in FES and CS are different, and that the processes may occur during various stages of the disease. Duration MMN may be a more sensitive biomarker during the early stages of patients with schizophrenia, while frequency MMN and theta power response to standard stimuli may be linked to a reduction in the cognitive functioning of patients with schizophrenia.

\section{REFERENCES}

Avissar, M., Xie, S., Vail, B., Lopez-Calderon, J., Wang, Y., and Javitt, D. C. (2017). Meta-analysis of mismatch negativity to simple versus complex deviants in schizophrenia. Schizophr. Res. 191, 25-34. doi: 10.1016/j.schres.2017.07.009

Blatow, M., Rozov, A., Katona, I., Hormuzdi, S. G., Meyer, A. H., Whittington, M. A., et al. (2003). A novel network of multipolar bursting interneurons generates theta frequency oscillations in neocortex. Neuron 38, 805-817. doi: 10.1016/S0896-6273(03)00300-3

Catts, V. S., Lai, Y. L., Weickert, C. S., Weickert, T. W., and Catts, S. V. (2016). A quantitative review of the postmortem evidence for decreased cortical $\mathrm{N}$-methyl-D-aspartate receptor expression levels in schizophrenia: how can we link molecular abnormalities to mismatch negativity deficits? Biol. Psychol. 116, 57-67. doi: 10.1016/j.biopsycho.2015.10.013

Chen, C. M. A., Stanford, A. D., Mao, X., Abi-Dargham, A., Shungu, D. C., Lisanby, S. H., et al. (2014). Gaba level, gamma oscillation, and working memory performance in schizophrenia. NeuroImage Clin. 4, 531-539. doi: 10.1016/j.nicl. 2014.03.007

Cohen, J. (1988). Statistical Power Analysis for the Behavioral Sciences, 2nd Edn. New Jersey, NJ: Lawrence Erlbaum Associates, Inc.

\section{LIMITATIONS}

There are two primary methodological limitation for the current study that should be considered. First, some of the FES patients were already receiving antipsychotic therapy, so we were unable to completely rule out the potential effects of concurrent therapeutic intervention. Secondly, the age at illness onset of CS is generally earlier than that of FES. As we wanted to ensure that age was matched between the subjects, there may be some heterogeneity between the subjects.

\section{AUTHOR CONTRIBUTIONS}

Y-BX and Q-JB contributed to manuscript preparation. Y-BX and QT performed the neurophysiological data analysis and statistics. Y-BX and YL oversaw MMN data/demographic data collection. C-MW looked over the MMN test. C-YW was in charge of design and implementation of the study and contributed to data interpretation.

\section{FUNDING}

This work was supported by the Major Brain Program of Beijing Science and Technology Plan (Z161100002616017), the National Science Foundation of China (81601169 and 81471365), the Beijing Municipal Administration of Hospitals Clinical Medicine Development of Special Funding Support (ZYLX201807 and XLMX201807), and Capital's Funds for Health Improvement and Research (2018-2-2123).

\section{ACKNOWLEDGMENTS}

The authors thank all the subjects for participating in this study.

Elvevåg, B., and Goldberg, T. E. (2000). Cognitive impairment in schizophrenia is the core of the disorder. Crit. Rev. Neurobiol. 14, 1-21. doi: 10.1615/ CritRevNeurobiol.v14.i1.10

Erickson, M. A., Ruffle, A., and Gold, J. M. (2016). A meta-analysis of mismatch negativity in schizophrenia: from clinical risk to disease specificity and progression. Biol. Psychiatry 79, 980-987. doi: 10.1016/j.biopsych.2015.08.025

Fisher, D. J., Grant, B., Smith, D. M., Borracci, G., Labelle, A., and Knott, V. J. (2011). Effects of auditory hallucinations on the mismatch negativity (MMN) in schizophrenia as measured by a modified 'optimal' multi-feature paradigm. Int. J. Psychophysiol. 81, 245-251. doi: 10.1016/j.ijpsycho.2011.06.018

Friedman, T., Sehatpour, P., Dias, E., Perrin, M., and Javitt, D. C. (2012). Differential relationships of mismatch negativity and visual pl deficits to premorbid characteristics and functional outcome in schizophrenia. Biol. Psychiatry 71, 521-529. doi: 10.1016/j.biopsych.2011.10.037

Fuentemilla, L., Marco-Pallarés, J., Münte, T. F., and Grau, C. (2008). Theta EEG oscillatory activity and auditory change detection. Brain Res. 1220, 93-101. doi: 10.1016/j.brainres.2007.07.079

Grzella, I., Müller, B. W., Oades, R. D., Bender, S., Schall, U., Zerbin, D., et al. (2001). Novelty-elicited mismatch negativity in patients with schizophrenia on admission and discharge. J. Psychiatry Neurosci. 26, 235-246. 
Haigh, S. M., Coffman, B. A., and Salisbury, D. F. (2017). Mismatch negativity in first-episode schizophrenia: a meta-analysis. Clin. EEG Neurosci. 48, 3-10. doi: $10.1177 / 1550059416645980$

Hay, R. A., Roach, B. J., Srihari, V. H., Woods, S. W., Ford, J. M., and Mathalon, D. H. (2015). Equivalent mismatch negativity deficits across deviant types in early illness schizophrenia-spectrum patients. Biol. Psychol. 105, 130-137. doi: 10.1016/j.biopsycho.2015.01.004

He, Y. L., and Zhang, M. Y. (1997). The positive and negative syndrome scale (PANSS) and its application. J. Clin. Psychiatry 7, 353-355.

Hermens, D. F., Ward, P. B., Hodge, M. A. R., Kaur, M., Naismith, S. L., and Hickie, I. B. (2010). Impaired MMN/p3a complex in first-episode psychosis: cognitive and psychosocial associations. Prog. Neuropsychopharmacol. Biol. Psychiatry 34, 822-829. doi: 10.1016/j.pnpbp.2010.03.019

Higuchi, Y., Sumiyoshi, T., Seo, T., Miyanishi, T., Kawasaki, Y., and Suzuki, M. (2013). Mismatch negativity and cognitive performance for the prediction of psychosis in subjects with at-risk mental state. PLoS One 8:e54080. doi: 10.1371/ journal.pone.0054080

Higuchi, Y., Tomonori, S., Tomohiro, M., Yasuhiro, K., Michio, S., and Tomiki, S. (2014). Mismatch negativity and p3a/reorienting complex in subjects with schizophrenia or at-risk mental state. Front. Behav. Neurosci. 8:172. doi: 10. 3389/fnbeh.2014.00172

Hsiao, F. J., Wu, Z. A., Ho, L. T., and Lin, Y. Y. (2009). Theta oscillation during auditory change detection: an MEG study. Biol. Psychol. 81, 58-66. doi: 10.1016/ j.biopsycho.2009.01.007

Javitt, D. C. (2015). Neurophysiological models for new treatment development in schizophrenia: early sensory approaches. Ann. N. Y. Acad. Sci. 1344, 92-104. doi: $10.1111 /$ nyas. 12689

Javitt, D. C., and Freedman, R. (2015). Sensory processing dysfunction in the personal experience and neuronal machinery of schizophrenia. Am. J. Psychiatry 172, 17-31. doi: 10.1176/appi.ajp.2014.13121691

Javitt, D. C., Lee, M., Kantrowitz, J. T., and Martinez, A. (2017). Mismatch negativity as a biomarker of theta band oscillatory dysfunction in schizophrenia. Schizophr. Res. 191, 51-60. doi: 10.1016/j.schres.2017.06.023

Javitt, D. C., Shelley, A. M., Silipo, G., and Lieberman, J. A. (2000). Deficits in auditory and visual context-dependent processing in schizophrenia. Arch. Gen. Psychiatry 57, 1131-1137. doi: 10.1001/archpsyc.57.12.1131

Javitt, D. C., and Sweet, R. A. (2015). Auditory dysfunction in schizophrenia: integrating clinical and basic features. Nat. Rev. Neurosci. 16, 535-550. doi: $10.1038 /$ nrn 4002

Kantrowitz, J. T., Epstein, M. L., Beggel, O., Rohrig, S., Lehrfeld, J. M., Revheim, N., et al. (2016). Neurophysiological mechanisms of cortical plasticity impairments in schizophrenia and modulation by the nmda receptor agonist d-serine. Brain 139, 3281-3295. doi: 10.1093/brain/aww262

Kantrowitz, J. T., Epstein, M. L., Lee, M., Lehrfeld, N., Nolan, K. A., Shope, C., et al. (2017). Improvement in mismatch negativity generation during, $d$-serine treatment in schizophrenia: correlation with symptoms. Schizophr. Res. 191, 70-79. doi: 10.1016/j.schres.2017.02.027

Kasai, K., Shenton, M. E., Salisbury, D. F., Hirayasu, Y., and Mccarley, R. W. (2003). Progressive decrease of left heschl gyrus and planum temporale gray matter volume in first-episode schizophrenia. Arch. Gen. Psychiatry 60, 766-775. doi: 10.1001/archpsyc.60.8.766

Koshiyama, D., Kirihara, K., Tada, M., Nagai, T., Koike, S., Suga, M., et al. (2017). Duration and frequency mismatch negativity shows no progressive reduction in early stages of psychosis. Schizophr. Res. 190, 32-38. doi: 10.1016/j.schres.2017. 03.015

Lee, M., Balla, A., Sershen, H., Sehatpour, P., Lakatos, P., and Javitt, D. C. (2017a). Rodent mismatch negativity $(\mathrm{mmn}) /$ theta neuro-oscillatory response as a translational neurophysiological biomarker for n-methyl-d-aspartate receptorbased new treatment development in schizophrenia. Neuropsychopharmacology 43, 571-582. doi: 10.1038/npp.2017.176

Lee, M., Sehatpour, P., Dias, E. C., Silipo, G. S., Kantrowitz, J. T., Martinez, A. M., et al. (2017b). A tale of two sites: differential impairment of frequency and duration mismatch negativity across a primarily inpatient versus a primarily outpatient site in schizophrenia. Schizophr. Res. 191, 10-17. doi: 10.1016/j. schres.2017.07.032

Lee, M., Sehatpour, P., Hoptman, M. J., Lakatos, P., Dias, E. C., Kantrowitz, J. T., et al. (2017c). Neural mechanisms of mismatch negativity dysfunction in schizophrenia. Mol. Psychiatry 108, 37-37. doi: 10.1038/mp.2017.3
Magno, E., Yeap, S., Thakore, J. H., Garavan, H., Sanctis, P. D., Javitt, D. C., et al. (2008). Are auditory-evoked frequency and duration mismatch negativity (MMN) deficits endophenotypic for schizophrenia? high-density electrical mapping in clinically unaffected first-degree relatives, first-episode and chronic schizophrenia. Biol. Psychiatry 64, 385-391. doi: 10.1016/j.biopsych.2008.03.019

Makeig, S., Jung, T. P., Bell, A. J., and Sejnowski, G. T. J. (1997). Blind separation of auditory event-related brain responses into independent components. Proc. Natl. Acad. Sci. U.S.A. 94, 10979-10984. doi: 10.1073/pnas.94.20.10979

Mondragón-Maya, A., Solís-Vivanco, R., León-Ortiz, P., Rodríguez-Agudelo, Y., Yáñez-Téllez, G., Bernal-Hernández, J., et al. (2013). Reduced p3a amplitudes in antipsychotic naïve first-episode psychosis patients and individuals at clinical high-risk for psychosis. J. Psychiatr. Res. 47, 755-761. doi: 10.1016/j.jpsychires. 2012.12.017

Näätänen, R., Sussman, E. S., Salisbury, D., and Shafer, V. L. (2014). Mismatch negativity (MMN) as an index of cognitive dysfunction. Brain Topogr. 27, 451-466. doi: 10.1007/s10548-014-0374-6

Näätänen, R., Tervaniemi, M., Sussman, E., Paavilainen, P., and Winkler, I. (2001). 'primitive intelligence' in the auditory cortex. Trends Neurosci. 24, 283-288. doi: 10.1016/S0166-2236(00)01790-2

Näätänen, R., Todd, J., and Schall, U. (2016). Mismatch negativity (MMN) as biomarker predicting psychosis in clinically at-risk individuals. Biol. Psychol. 116, 36-40. doi: 10.1016/j.biopsycho.2015.10.010

Oranje, B., Aggernaes, B., Rasmussen, H., Ebdrup, B. H., and Glenthøj, B. Y. (2017). Selective attention and mismatch negativity in antipsychotic- naïve, first-episode schizophrenia patients before and after 6 months of antipsychotic monotherapy. Psychol. Med. 47, 2155-2165. doi: 10.1017/S0033291717000599

Pang, Y. X., Zhang, J., Yang, C. L., Cang, Y., and Wang, X. L. (2011). Application of WAIS-RC short forms and adult intelligence disability scale in mental impairment assessment. Fa Yi Xue Za Zhi 27, 189-192.

Perez, V. B., Woods, S. W., Roach, B. J., Ford, J. M., Mcglashan, T. H., Srihari, V. H., et al. (2014). Automatic auditory processing deficits in schizophrenia and clinical high-risk patients: forecasting psychosis risk with mismatch negativity. Biol. Psychiatry 75, 459-469. doi: 10.1016/j.biopsych.2013.07.038

Randeniya, R., Oestreich, L. K. L., and Garrido, M. I. (2018). Sensory prediction errors in the continuum of psychosis. Schizophr. Res. 191, 109-122. doi: 10. 1016/j.schres.2017.04.019

Salisbury, D. F., Kuroki, N., Kasai, K., Shenton, M. E., and Mccarley, R. W. (2007). Progressive and interrelated functional and structural evidence of post-onset brain reduction in schizophrenia. Arch. Gen. Psychiatry 64, 521-529. doi: 10. 1001/archpsyc.64.5.521

Salisbury, D. F., Polizzotto, N. R., Nestor, P. G., Haigh, S. M., Koehler, J., and Mccarley, R. W. (2017). Pitch and duration mismatch negativity and premorbid intellect in the first hospitalized schizophrenia spectrum. Schizophr. Bull. 43, 407-416. doi: 10.1093/schbul/sbw074

Salisbury, D. F., Shenton, M. E., Griggs, C. B., Bonner-Jackson, A., and McCarley, R. W. (2002). Mismatch negativity in chronic schizophrenia and first-episode schizophrenia. Arch. Gen. Psychiatry 59, 686-694. doi: 10.1001/archpsyc. 59.8.686

Shi, C., Kang, L., Yao, S., Ma, Y., Li, T., Liang, Y., et al. (2015). The MATRICS consensus cognitive battery (MCCB): co-norming and standardization in china. Schizophr. Res. 169, 109-115. doi: 10.1016/j.schres.2015.09.003

Thönnessen, H., Zvyagintsev, M., Harke, K. C., Boers, F., Dammers, J., Mathiak, K., et al. (2008). Optimized mismatch negativity reflects deficits in schizophrenia patients in a combined EEG and MEG study. Eur. Psychiatry 23, S135-S135. doi: 10.1016/j.eurpsy.2008.01.852

Todd, J., Michie, P. T., Schall, U., Karayanidis, F., Yabe, H., and Näätänen, R. (2008). Deviant matters: duration, frequency, and intensity deviants reveal different patterns of mismatch negativity reduction in early and late schizophrenia. Biol. Psychiatry 63, 58-64. doi: 10.1016/j.biopsych.2007.02.016

Toyomaki, A., Kusumi, I., Matsuyama, T., Kako, Y., Ito, K., and Koyama, T. (2008). Tone duration mismatch negativity deficits predict impairment of executive function in schizophrenia. Prog. Neuropsychopharmacol. Biol. Psychiatry 32, 95-99.

Umbricht, D., Javitt, D., Novak, G., Bates, J., Pollack, S., Lieberman, J., et al. (1999). Effects of risperidone on auditory event-related potentials in schizophrenia. Int. J. Neuropsychopharmacol. 2, 299-304. doi: 10.1017/S1461145799001595

Umbricht, D., and Krljes, S. (2005). Mismatch negativity in schizophrenia: a meta-analysis. Schizophr. Res. 76, 1-23. doi: 10.1016/j.schres.2004.12.002 
Weickert, T. W., Goldberg, T. E., Gold, J. M., Bigelow, L. B., Egan, M. F., and Weinberger, D. R. (2000). Cognitive impairments in patients with schizophrenia displaying preserved and compromised intellect. Arch. Gen. Psychiatry 57, 907-913. doi: 10.1001/archpsyc.57.9.907

Womelsdorf, T., Valiante, T. A., Sahin, N. T., Miller, K. J., and Tiesinga, P. (2014). Dynamic circuit motifs underlying rhythmic gain control, gating and integration. Nat. Neurosci. 17, 1031-1039. doi: 10.1038/nn.3764

Wynn, J. K., Sugar, C., Horan, W. P., Kern, R., and Green, M. F. (2010). Mismatch negativity, social cognition, and functioning in schizophrenia patients. Biol. Psychiatry 67, 940-947. doi: 10.1016/j.biopsych.2009.11.024
Conflict of Interest Statement: The authors declare that the research was conducted in the absence of any commercial or financial relationships that could be construed as a potential conflict of interest.

Copyright (C) 2019 Xiong, Bo, Wang, Tian, Liu and Wang. This is an open-access article distributed under the terms of the Creative Commons Attribution License (CC BY). The use, distribution or reproduction in other forums is permitted, provided the original author(s) and the copyright owner(s) are credited and that the original publication in this journal is cited, in accordance with accepted academic practice. No use, distribution or reproduction is permitted which does not comply with these terms. 